\title{
A Review of Early Childhood Education (ECE) in Bangladesh: Status and Impact
}

\author{
Rafiath Rashid ${ }^{1, *} \&$ Abdeljalil Akkari ${ }^{2}$ \\ ${ }^{1}$ Head of Early Childhood Development Programme, BRAC International, 75 Mohakhali, \\ BRAC Center, Dhaka 1212, Bangladesh \\ ${ }^{2}$ Faculty of Psychology and Education Sciences, University of Geneva, 24 rue du \\ Général-Dufour, 1211 Genève 4, Switzerland \\ *Corresponding author: Head of Early Childhood Development Programme, BRAC \\ International, 75 Mohakhali, BRAC Center, Dhaka 1212, Bangladesh. E-mail: \\ rafiathrashid@gmail.com
}

Received: December 29, 2019 Accepted: February 10, 2020 Published: February 15, 2020

doi:10.5296/ije.v12i1.16150 URL: https://doi.org/10.5296/ije.v12i1.16150

\begin{abstract}
This literature review has evaluated the effort and promise of investing in early childhood education in the context of Bangladesh in terms of policy, access, quality and impact. The findings on access showed that with improved policies and provisions from government, there has been a dramatic increase in pre-primary enrolment where along with government other private providers have come up in the early-years education space contributing significantly in terms of providing access. The review could not find consistent and disaggregated data on the access and provisions for the younger cohort of children aged 3 to 5 years old who are supposed to be under early childhood education provisions according to the ECCD policy. The review found evidences of positive correlation between quality and child learning outcomes in the context of Bangladesh, however, the criteria, definition and interpretation of 'quality' for ECE is yet to be studied and implemented. It is quite evident from the review that there are variation of teachers' qualifications and lack of materials and evidences of pedagogical practices in the ECE classrooms. Along with quality, this review found impact of ECE in two areas: school readiness and primary school achievement.
\end{abstract}

Keywords: Early Childhood Education, Preschool Education, impact, access, quality, Early Childhood Education in Bangladesh 


\section{Introduction}

Early childhood development means the cognitive, social, emotional and motor development of children from conception to eight years. Children grow and develop rapidly during this period and neurological or brain development is largely a result of the learning that takes place starting at birth and during the earliest years of life (Bradley, 1998). Early Childhood is a crucial phase of growth and development which influence a range of health and social outcomes across the entire life course of an individual's life (United Nations, 2010; Irwin, Siddiqi \& Herzman, 2007). Early-life investment is important for at-risk children in low-income families (Rossin-Slater, 2015). Furthermore, children who get the access to quality early learning opportunities, have enhanced cognitive, verbal, and social development, which is maintained into the first few years of school and enter school better prepared (Barnett, 1995; Entwisle, 1995). According to Heckmen (2007), “As a society, we cannot afford to postpone investing in children until they become adults, nor can we wait until they reach school age - a time when it may be too late to intervene". Early childhood education should have received the similar focus as primary education over the past twenty years because it lays the foundation for learning and development (UNESCO, 2006). In this regard UNESCO (2006) emphasized on the urgent necessity for investing in access and quality, and support for families and says, "This requires government commitment and leadership, around which other stakeholders, including international and donor communities, can be mobilized". Similarly, a call to action by the Consultative Group on Early Childhood Care and Development (CGECCD) (2013) says, "Investment of at least $15 \%$ of international education aid should go into pre-primary and early childhood education programs". In this context, many countries around the world has put ECE in their priority agenda, including Bangladesh. This review will evaluate the effort and promise of investing in childhood in the context of Bangladesh in terms of access, quality and impact.

\section{Purpose and Methodology}

The purpose of this literature review is to understand the current status, access and impact of Early Childhood Education (ECE) in Bangladesh. The review began with a thorough literature review that includes empirical articles, policy documents and programme reports available in the field of ECE primarily on Bangladesh. Relevant research papers and articles on global and South Asian contexts have also been reviewed. MyAthens (https://my.openathens.net) and Google Scholar (https://scholar.google.ch/) are the two search engines which have been used to search relevant articles using key words such as: Early Childhood Education, Early Childhood Development, Preschool education, Bangladesh and Impact of Early Childhood Education.

A total of 50 articles have been reviewed initially from the period of 2004 to 2018. Finally, 20 empirical articles from 2006 to 2018 relevant to early learning/education in the context of Bangladesh have been included in this review. Articles related to health and nutrition in the field of Early Childhood Development have been excluded from the review since the focus was only on early education and learning. A couple of articles have been found which 
evaluated the impact of a mathematics intervention layered on existing preschool which have been excluded since they do not reflect on the overall quality and impact of the preschool education on children. The key findings from these papers have been analyzed and organized thematically focusing on policy, practice and evidences. Considering the limited number of empirical articles available on the context of Bangladesh, this review has considered relevant article since 2006.

Table 1. The Reviewed Articles Categorized in Three Groups

\begin{tabular}{llc}
\hline \multicolumn{1}{c}{ Categories } & \multicolumn{1}{c}{ Types of articles } & No. of articles \\
\hline Category 1: & International Journal & 11 \\
Nature of publication & National Journal & 3 \\
& Empirical research reports & 6 \\
& Total & 20 \\
Category 2: & Impact Evaluation & 15 \\
Research design & Socio-cultural study & 3 \\
& Sectorial review & 2 \\
& Total Classroom & 20 \\
Category 3: & Intervention-comparison & 8 \\
Research methodology & Randomized control trial & 3 \\
& Qualitative - Coservation/FGD/KII/Literature & 5 \\
& review & 4 \\
& Mixed method & 20 \\
\hline
\end{tabular}

This review included articles published in international and national journals, and also a number of research/evaluation reports (as independent publications) which followed scientific research methods. International journals include journals of educational studies, early childhood and health research. Three main types of empirical articles could be found: impact evaluation, socio-cultural study and sectorial review which included literature review and descriptive research. Impact evaluations followed methodologies such as: intervention-comparison designs and randomized controlled trials, while socio-cultural studies are mainly qualitative studies looking into pedagogy and perception. The sectorial reviews mainly followed mixed method including both qualitative and quantitative approaches.

The articles reviewed have highlighted these four broad themes which have been used as a conceptual framework to organize the findings. The impact section is further divided into two sub-themes according to the available literature considered for review. The findings will provide both descriptive and analytical review of the literatures relevant to the context of Bangladesh following this conceptual framework: 


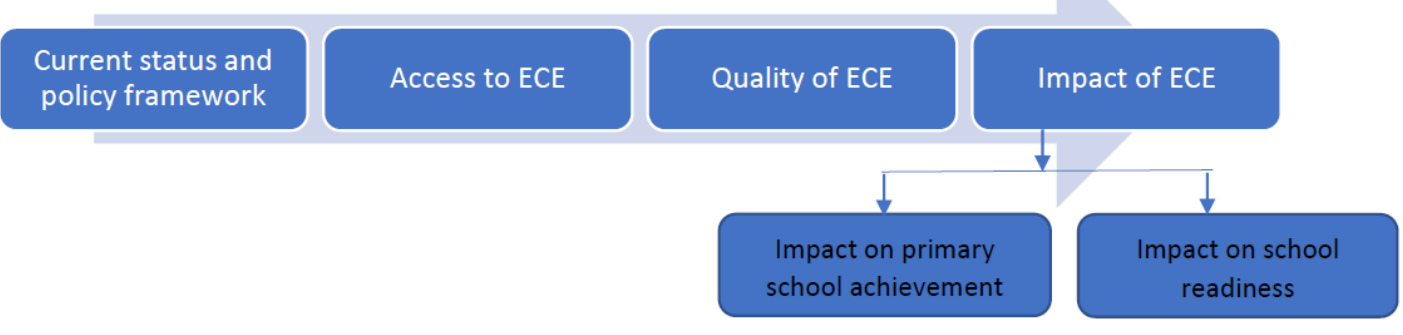

Figure 1. The Analytical Framework of Review

\section{Findings}

\subsection{Current Status and Policy Framework}

Bangladesh is a small yet very densely populated country with about 166 million people and an area of 144,000 square kilometers. Bangladesh achieved its independence from Pakistan in 1971 and now known as the People's Republic of Bangladesh. Over the past decade, Bangladesh has achieved rapid economic growth with an average rate of 6.1 percent per year (World Bank, 2017).

However, this rapidly developing country has its own challenges when it comes to social services such as: creating learning opportunities for young children. About $18 \%$ children are below 9 years. About $9 \%$ children are under 5 years age (ECDAN, 2018). Annual birth rate is about 3.1 million. Although Bangladesh has achieved great progress in primary enrolment rate and catching up on the secondary enrollment rate, early childhood education is still lagging behind alarmingly. The primary gross and net enrolment rates are GER: $111.09 \%$, NER: $90.5 \%$ (F: 93\%, M: 88\%) respectively (UNESCO, 2017). Average completion rate has reached 79.6 percent (World Bank, 2017). At the secondary level GER: 67.27\%, NER: 61.55\%, (F: 66.55\%, M: 56.78\%) (UNESCO, 2017). On the other hand, NER at pre-primary is $52.6 \%$ and attendance rate in ECE is about 13\% (World Bank, 2017).

The government launched the Pre-primary Education (PPE) initiative, under the Second Primary Education Development Programme (PEDP II), by introducing "baby classes" before primary for children under six years old (MoPME, 2013). This is primarily the result of evidence-based advocacy done by national and international NGOs highlighting importance of quality pre-primary education for children's development (UNESCO, 2015).

In 2008, Operational Framework for Pre-primary Education (PPE) has been adopted in Bangladesh which states that, "Pre-primary education is the developmental and educational support provided to the child in the age range of 3 to $<6$ years...irrespective of the child's physical, mental and social status" (MoPME, 2013). This framework was also a collaborative effort by the non-governmental organizations (NGO), particularly Bangladesh Early Childhood Development Network (BEN), and was taken up for implementation in 2010 
under PEDP II after approval by Ministry of Primary and Mass Education (MoPME) (UNESCO, 2015). Later, in the National Education Policy, 2010 pre-primary education (PPE) had been included as part of universal primary education making one-year education mandatory for children age 5, prior to entering grade 1 of primary school (MoPME, 2013).

While all of this work being done in pre-primary, the early learning opportunity for the younger cohort ( 3 to 5 ) is still largely provided by the NGOs and private sector. Bangladesh's government has established a new policy and institutional framework for the ECD subsector. The Comprehensive Early Childhood Care and Development (ECCD) Policy adopted by the Ministry of Women and Children's Affairs which has been approved in November 2013. Currently, an implementation plan is underway under the MoWCA, while the Early Learning and Development Standards (ELDS) for ECCE is going through age validation process. A national pre-primary curriculum and textbook, along with teachers' guide, is also being implemented nationally.

Despite having the policies and frameworks in place, few gaps have been identified in a number of research and reports through this review. A World Bank study (2017) examined the status of Early Childhood Development (ECD) efforts in Bangladesh and presented the results of a rigorous impact evaluation of an Early Childhood Stimulation (ECS) program. It argued that, while policymakers increasingly recognize the importance of Early Childhood Development (ECD) interventions, empirical evidence regarding their impact on human capital formation remains limited. The evaluation also suggests that successful ECD program does not necessarily require labor- or capital-intensive interventions (World Bank, 2017). While an ECD program may be most effective when it offers a holistic package of educational, health and social protection interventions (Denboba et al. 2014), the impact evaluation demonstrates that an add-on effort on Early Childhood Stimulation (ECS) is able to generate substantial contribution to improving ECD outcomes. It was recommended in the report that a comprehensive follow-on policy note on ECD, from early stimulation to pre-primary education would be necessary. Issues to be addressed in such a policy note include: the quality of service provision, financing arrangements, governance, and policy coordination (World Bank, 2017).

UNESCO (2015) conducted a case study on Bangladesh involving an in-depth examination of the Pre-primary Education (PPE) and School Learning Improvement Plan (SLIP) initiatives. Some of the relevant key policy recommendations mentioned in UNICEF (2015) were "to focus more attention on urban poor children, to develop and trial upazila-based universal primary education (including pre-primary) planning and management, to provide policy support for greater authority with accountability at the school level, to address the issue of silent exclusion, and to increase resources for education". In addition, there were recommendations for quality improvement of PPE services by providing dedicated spaces and teachers for PPE in every school, providing support for RNGPS and ibtedayee madrasas (private religious schools) for extending high-quality services, broadening school-level authority with accountability and ensuring an effective coordination and collaboration approach in PPE nationally and locally (UNESCO, 2015). Another study by Sikder and Banu (2017) has reviewed the relevant policies, practices research in the Early Childhood 
Education sector (ECE). This paper has found and thoroughly discussed the gaps in this sector in terms of unavailability of reliable data; pockets of exclusion such as: remote rural areas, hilly terrains, islands and coastal belts, river banks, wetlands, brothels, tea gardens, jails etc.; lack of appropriate tools and capacity to assess developmental progress along the milestones; lack of sufficient initiatives for parental awareness.

Despite having these policy, governance, services, quality, data and access related gaps the ECE sector has progressed significantly in terms of access with the government initiatives and coordinated effort by the NGOs.

\subsection{Access to ECE}

With the launch of the PPE initiative in 2010, participation in pre-primary education has been tripled, as stated by UNESCO (2015), "increasing it from 895,000 in 2010 to about 2.5 million in 2012". In 2010, a total of 18 government ministries and more than 200 organizations were involved in implementing ECD programs (Chinen and Bos, 2016). As a result, an estimated $55 \%$ of 5 to 6 years old children were participating in the one-year pre-primary courses implemented by government, private and NGO-run pre-primary centres, where again the contribution of NGOs was quite significant serving one-fourth of the children participating in preprimary education (UNESCO, 2015).

More than 93,000 primary education institutions in Bangladesh offer pre-primary classes, which together served 2.9 million children in 2015. In line with the NEP 2010 and the operational framework for PPE, the government has progressively expanded educational outreach to young children, starting with one year of PPE in all public primary schools. Currently, $99 \%$ of public primary schools and $95 \%$ of newly nationalized primary schools offer PPE (DPE, 2015).

The Education Watch (2013) report, which was a national study which had mapped the status of pre-primary education in Bangladesh, found that although the national gross enrolment ratio at pre-primary was $161.6 \%$, while the net enrolment rate was $52.6 \%$; higher for urban areas than those of the rural areas with no gender difference. This variation between gross and net enrolment indicates the overwhelming enrolment of over and/or under age children at pre-primary where about two-third of the enrolled children were over or under the official age of five. This may also indicate the high demand of ECE, particularly in the urban areas. The report also found that the enrolment rate was higher for children from socio-economically well-off families (Nath et al, 2013).

The findings on access showed that Bangladesh has achieved a significant increase in pre-primary enrolment rate since post-2008 period, increasing the net enrolment rate of $52.6 \%$ in pre-primary in 2013, which is four times since then. Although government has pushed its effort for creating more access in pre-primary, the overall enrollment decreased in government schools while it has increased in private schools. It was found that kindergartens were providing the highest access to pre-preprimary education in Bangladesh followed by government and NGOs, providing access to about $28 \%, 23 \%$ and $22 \%$ of total enrolled children respectively (Nath et al., 2013). This shows that with improved policies and 
provisions from government, other private providers have also come up in the early years education space and contributing significantly in terms of providing access. While government provision contributed nationally, but mainly in the rural areas; private schools have catered from children in urban and semi-urban areas.

The review could not find consistent and disaggregated data on the access and provisions for the younger cohort of children aged 3 to 5 years old who are supposed to be under early childhood education provisions according to the ECCD policy. It is clear from the data that both under aged and over aged children are enrolled in the existing one-year pre-primary classes which includes 3 to 5 years old children. However, there is no age specific provision available under the government system as yet. According to World Bank (2017) report, attendance rate in any kind of ECCE programs is about $13 \%$ for 3 to 5 years old children.

Apart from government, the early childhood education activities for 3 to 6 years old children in Bangladesh consist of various initiatives and programs under different service providers. From the very beginning of the evolution of early childhood education in Bangladesh, NGOs were the vanguard of pre-primary education and implemented significant numbers of preschools/early learning centers, namely, GSS, BRAC, Save the Children, Plan International, Care Bangladesh, Action Aid, Dhaka Ahsania Mission, FIVDB, CARITAS, Phulki, along with the other members of Campaign for Popular Education and Bangladesh ECD Network. A number of actors namely, Bangladesh Shishu Academy (BSA) under the Ministry of Women and Children's Affairs (MOWCA), UNICEF and few other NGOs, target and work in the pockets of exclusion in geographically vulnerable and disaster-prone locations, and hard to reach areas such as: hill tracts, haor area, coastal area, water-locked islands (char), tea gardens, brothels, prisons, and urban slums. There are also religious institutions providing ECE services such as: madrasas, mosque based maktabs and temples (MoPME, 2013).

While the large and rising number of individual initiatives has greatly expanded the range of ECD services in Bangladesh, service quality and availability are highly uneven (World Bank, 2017). Nath and Sylva (2007) in their study, Children's Access to Preschool Education in Bangladesh, recommended that "an educational policy targeting poor and socially disadvantaged children is urgently needed to provide under five children appropriate education for their needs". In order to expand access to pre-primary, Bangladesh has a big challenge. The widening of access presupposes the mobilization of families for financing and the use of a multitude of providers: NGOs, religious organizations, private entrepreneurs. However, this diversification of supply necessarily implies difficulties in standardization and heterogeneous quality.

\subsection{Quality of ECE}

Naudeau, S \& Hasan, R. (2015) mentioned in Early Childhood Development: A Review of the Global Evidence that, "the impact of quality center-based care has been documented in high-income countries. Recent evidence shows that quality daycare and preschools can have significant positive effects on a child's overall development and school readiness in a wider range of countries, including in Argentina, Bangladesh, Chile, China, Colombia, Costa Rica, Kenya, Uganda, Uruguay, and Zanzibar, to name a few (Engle et al. 2011)". Here, the 
emphasis has to be on 'quality' center-based ECD services as multiple studies have found that poor quality service cannot achieve the same level of impact (Naudeau, S \& Hasan, R. 2015).

In Bangladesh, Shahjamal and Nath (2008), in their study evaluating BRAC pre-primary programme, recommended for high quality preschool programme and age appropriate curriculum for later success in primary education. Preschool experience assumed to have a higher impact on children's learning achievement and this assumption was confirmed through the impact study on Succeed project where effective correlations have been found between the quality of the preschool attended by the child, measured by Early Childhood Environment Rating Scale (ECERS), and first-grade achievement (Aboud, Hossain \& O'gara, 2008). Aboud (2006) found that "higher ECERS qualities were empirically associated with higher cognitive outcomes among poor rural Bangladeshi children".

Education Watch (2013) report was a national study which had mapped the status of pre-primary education in Bangladesh primarily focusing on access, provisions and relevant policies. This study also thoroughly reviewed the quality of ECE services available in Bangladesh in terms of the status of teachers' training, physical facilities of the pre-primary classrooms and availability of relevant materials. It found that more than half of the pre-primary teachers from all kinds of pre-primary service providers had any kind of teacher training and among them $35 \%$ had training particularly on pre-primary education. Among those who received training in pre-primary education, NGOs leading with over $95 \%$ of their teachers trained, followed by government $(53.8 \%)$ and mosque based $(52.5 \%)$ pre-primary services. Only $6.5 \%$ of the pre-primary teachers in the kindergartens were found to be trained in pre-primary education. Irrespective of the status of teachers' training, this study didn't find any difference in terms of pedagogical practices and teaching techniques between pre-primary and primary (Nath et al, 2013).

In terms of physical facilities, it was found that although majority of the pre-primary classes were held in a traditional classrooms setting. However, about $11 \%$ of them were using other spaces in the school building such as: verandas, head teachers' offices, rooftops, stair-rooms or even open spaces due to lack of infrastructural facilities. In terms of basic facilities such as: cleanliness, light and airflow about $44 \%$ of the classrooms was found to be fully satisfactory. Availability of adequate materials was found to be a real challenge in the pre-primary schools since about 39\% schools had no teaching-learning and play materials. Among the materials found, charts were the mostly available teaching-learning material which was found to be available in $53.3 \%$ schools. Toys, some kind of physical exercise items and materials for drawing or painting were available in about $36 \%, 34 \%$ and $29 \%$ of the schools respectively. Only about $12 \%$ schools had any instruments or props related to singing, dancing and drama (ibid, 2013).

Education Watch (2013) report has also revealed interesting findings regarding the mosque-based schools where it found that about half of the pre-primary teachers were untrained and a quarter of them were madrasa educated themselves. From a pedagogical perspective the mosque based schools were quite different from others since activities like rhymes, singing, dancing, art, drama, hanging pictures, charts on the wall etc. were not 
allowed in the mosques due to some religious restrictions. Therefore, about $86 \%$ of these schools had no other materials except for books (ibid, 2013).

From the pedagogical aspect, since play has been recognized by scholars and researchers of child development as an important pedagogical tool for children's social, emotional, intellectual and physical development (Walsh, Sproule, McGuinness, Trew, \& Ingram, 2010), there has been a number of studies conducted to explore this pedagogical approach in the ECE context of Bangladesh. It has been found that implementation of play-based teaching and learning approach in the government pre-primary classrooms in Bangladesh has its own limitations. This includes newly recruited teachers with inadequate training, large number of students, lack of sufficient space and conservative use of play materials. With a high teacher-student ratio, classroom management seemed to be the most challenging task for them because of the large number of children in pre-primary (Rashid and Jahan, 2018). This finding can be complimented by a similar study conducted by Chowdhury \& Rivalland (2011) which explored the conceptual understanding of play-based pedagogy in Bangladesh through a socio-cultural study on government pre-primary schools and found that, "young children's active and interactive joyful activities, such as working with learning apparatuses, physical exercises, singing, acting, rhyming, games, outdoor plays and drawing, were described as play". The study captured the situation and current pedagogical practices from a 'play-lens' during the immediate pre-expansion period by the government. A separate article by the same authors (Chowdhury \& Rivalland, 2012) found that the concept of learning through play in a given society is defined by the "socio-cultural, historical, economic and political factors" as in this study "parents considered play as leisure while teachers acknowledged it as accelerating young children's learning and aiding their preparation for school". This explains why child-centered, play-based pedagogical approach is not yet a reality compared to rote-memorization and teacher-centric approach even in ECE classrooms.

Therefore, although the positive correlation between quality and child outcome has been established in the context of Bangladesh, the criteria, definition and interpretation of 'quality' for ECE is yet to be studied and implemented. It is quite evident from the review that there are variation of teachers' qualifications and lack of materials and evidences of pedagogical practices in the ECE classrooms.

\subsection{Impact of ECE Programs/Interventions}

Most of the research reports available on the impact of ECE in the context of Bangladesh are focused on evaluation of Ngo-run ECE programs. A number of systematic research-based evaluations in Bangladesh have shown positive impact of ECE programs on children's learning and development. The key findings have been organized under the following themes:

\subsubsection{Impact on School Readiness}

According to the Multiple Indicator Cluster Survey (MICS) for 2012-13, only 21.2 percent of children between the ages of three and five are on track in terms of literacy and numeracy. Despite descriptive statistics showing that cognitive and linguistic skills among children soon after birth, at age 3- 6 months, are broadly consistent with international standards, they 
continuously decline among older age groups and only 21 percent of age 36 to 59 months old reach their literacy and numeracy milestones (World Bank, 2017). Therefore, school readiness has been one key focuses of the impact studies reviewed. Janus (2007) defined "children's readiness for school as the skills children should possess in order to be able to learn effectively in school" and skills in turn have been conceptualized through the five developmental domains, such as: physical development, social competence, emotional maturity, language and cognitive development, and communication skills (Arnold, Bartlett, Gowani, and Shallwani, 2008). A number of studies are available in the context of Bangladesh which found positive impact of ECE interventions on cognitive and social development of children. However, no studies could be found which particularly measured emotional development of children, for example, in terms of self-regulation, self-identity, empathy etc. (Boyd J. et al. 2005).

Aboud (2006) found out that a preschool program in rural Bangladesh providing a half-day program for six days a week, with free play, stories, and instruction in literacy and math found positive impact on cognitive and social outcome of children. It specifically found that, "After controlling the differences in child's age, nutritional status, mother's education, and assets: preschool children performed better than the comparison children on measures of vocabulary, verbal reasoning, nonverbal reasoning, and school readiness. On some indicators of social development during play, preschool children performed better, though not on the cognitive aspects of play" (Aboud, 2006). Another short-term pilot intervention study revealed positive impact in terms of cognitive and social outcomes (Moore, Akhter \& Aboud, 2008). This study compared a regular NGO run preschool program in rural Bangladesh with a new and revised pilot intervention using a pre-post intervention-control design. It found that although the quality of both intervention and control program improved from baseline, the revised pilot program showed higher impact on quality and developmental outcomes, particularly on some cognitive and social outcomes, after seven months of interventions (Moore, Akhter \& Aboud, 2008). In both the studies, the key instruments used to measure school readiness were: Wechsler Preschool and Primary Scale of Intelligence (WPPSI - III) to measure the cognitive aspects such as: language and reasoning, and Rubin's Play Observation Tool (POS) to measure social aspects of school readiness. These tools are international tools which have been implemented in the context of the research.

However, there are other studies incorporated in this review which did not use international measurement instruments, but have found positive effect on different aspects of school readiness. Proulx and Kabir (2011) found a substantial effect of early childhood education on children's school readiness, which includes cognition, social and emotional development, and has a higher impact mainly on the areas of language and literacy development for children with low parental education. A mid-term evaluation, following a qualitative approach, of a comprehensive ECD programme implemented by BRAC, that included center-based preschool program for 3 to 5 years old children and parenting interventions, showed improvement in children's communication skills, improved participation, and improved cognitive and social development (Zaman, S. S. et al., 2015). Another small study conducted by Nahar and Rony (2013) on a slum based pre-primary catering for 5 to 6 years old children 
found that "all the children $(100 \%)$ in the sample (20) achieved the competencies in pre-mathematics". It used an instrument developed by the researchers based on the developmental domains. Although score on physical and motor development (85\%) and social-emotional development (55\%) were also good, score related to other domains, such as: language and communication, creative and aesthetic skills, science and technology, was at less than $50 \%$ while health and security was only at $15 \%$. However, question remains regarding the reliability of the measurement instrument and process followed since there was limited information found regarding the tool development process (Nahar and Rony, 2013).

Other impact studies have measured children's developmental outcomes focusing on the evaluations of parenting interventions. An impact evaluation by World Bank (2017) conducted between 2013 and 2015 focused on a set of Early Childhood Development (ECD) interventions implemented under Save the Children's Early Childhood Stimulation (ECS) program. This program included parents' counseling sessions along with sharing informational materials to improve parental knowledge of good childrearing practices and the impact study on this revealed that the ECS program yielded positive and statistically significant impacts on cognitive, linguistic and physical development as well as modest improvements in socio-emotional development (World Bank, 2017). Most of the similar studies are conducted to measure the impact of parenting interventions on the growth and development of 0 - 5 years old children (Aboud, 2007; About et al., 2008; Aboud and Akhter, 2011; Akhter, 2017).

Although there is a clear indication from the studies above that preschool experience has positive impact on children's school readiness in the context of Bangladesh, at least on the cognitive aspect of it. However, there are studies found which did not find any impact as such. One study evaluating the effect of the Comprehensive Child Development Program (CCDP) implemented by BRAC found no effect on school readiness scores of children suggesting the importance of further evaluation of the program (Khanom et. al., 2013). Another World Bank (2017) study found that the indicators of children's cognitive development and socio-emotional skills are low, with large disparities by income and education level of families. It is because multiple factors, such as: socio-economic status, home learning environment and the quality of the ECD program where children are participating, influence children's development and readiness for school (Arnold C., Bartlett, K., Gowani, S. and Shallwani, S., 2008). Therefore, the discussion above underscores the urgent need for action to safeguard the health, wellbeing and socioeconomic potential of Bangladeshi children (World Bank, 2017).

\subsubsection{Impact on Primary School Achievement}

The impact of ECE interventions on primary school achievement is one of the key evidences required for ECE advocacy. Globally many evidences are available showing the positive impact of early childhood education on primary school achievement (Blau and Currie, 2004; Heckman, 2007). In Bangladesh, very few studies have been conducted to measure this impact. Among them a study evaluating the Succeed project implemented by Save the Children in Bangladesh found that the children who went through the early learning program 
of Succeed project "performed better in Grade 1 than baseline children with no preschool experience, on four out of five competencies - namely, speaking, reading, writing and oral math" (Aboud, Hossain \& O'gara, 2008). They also explored the impact of school and home-based pre-schooling and found that both programs have the same level of impact on school achievement. In another study by Aboud and Hossain (2011), on investigating the impact of pre-primary school on primary achievement, it has been found that "children who attended preschool did better in reading, writing, listening and speaking" compared to children who did not attend any preschool in grade 1 and 2. A study by Moore, Akhter \& Aboud (2008) found that children in the intervention group were better prepared for grade 1, particularly on the key concepts of math and language, which as a result reflected in greater improvements on school readiness. In all of these studies, achievement in primary school have been measured in terms of reading, writing and speaking and only in grade 1 . The impact in terms of other behavioral skills, particularly social-emotional skills, and on retention in primary school have not been measured. Duflo (2001) found that attending pre-primary school not only had positive effect on third grade standardized language and math scores, but also had "positively affected student's behavioral skills such as attention, effort, class participation, and discipline". A longitudinal Study on early childhood impact, by Magnuson, Ruhm and Waldfogel (2005) revealed that "ECE was associated with higher reading and mathematics skills at primary school entry, but that these correlations disappeared by the end of first grade". Blau \& Currie (2004) noted that "behavioral skills is as important as cognitive skills to future success in life". Overall, it has been found that in the context of Bangladesh, the evidence on the impact of primary school achievement is limited to academic success, mainly in terms of literacy and numeracy in early primary grades (grade 1 and 2).

\section{Conclusion: Identified Research Gaps in Bangladesh}

According to the World Bank (2017) report, compared to other sub-sectors of education, evaluation of ECD programs has been limited in Bangladesh, and more extensive data and further impact evaluations could greatly improve the effectiveness of ECD interventions. This review has identified few major gaps in research in ECE, such as:

- Further studies are required to explore the impact of ECE interventions on the most marginalized groups, such as: children with disabilities (CWD), indigenous children, children from remote geographies (e.g. living in island, river banks, wetlands, coastal belts, hill tracts etc.), and refugee children.

- No studies have been found on the ECE services, quality and impact on Madrassa section of education.

- Studies on the impact on developmental outcome, school readiness and service quality are quite scattered with varied population, age groups, sample size and objectives. No review has been found with a systematic framework to capture impact of ECE in Bangladesh compared to other relevant contexts. 
- An understanding of parents and teachers' perception about ECCE and school readiness could add value.

- No studies have been found which captured the key international and national influencers in shaping the policy context for ECE and their contribution in the sector (e.g. World Bank, UN, INGOs, NGOs etc.).

- Further studies required to explore the quality issues in different types of ECE providers, such as: government, NGO, Madrassa, private etc.

- No studies have captured the existing capacity on ECCE research in Bangladesh.

- No studies have explored the financing arrangements, and subsector governance and coordination efforts to address the access and quality issues in this sector.

Therefore, further studies would be essential exploring the above-mentioned gaps in research in the ECE sector which would contribute to advancing the ECE agenda in Bangladesh, including a comprehensive review of the current state of the ECE sector. Compared to other sectors in education and social development, a weakness of the ECE sector is that little knowledge of ECE has yet been accumulated. Developing a systematic exploratory research framework to address some of the mentioned gaps could add great value in terms of producing necessary evidences and policy recommendations in the ECE sector of Bangladesh.

\section{References}

Aboud, F. E. (2006). Evaluation of an early childhood preschool program in rural Bangladesh. Early Childhood Research Quarterly, 21(1), 46-60. https://doi.org/10.1016/j.ecresq.2006.01.008

Aboud, F. E. (2007). Evaluation of an Early Childhood Parenting Programme in Rural Bangladesh. Journal of Health, Population and Nutrition, 25(1). Retrieved on from https://www.ncbi.nlm.nih.gov/pmc/articles/PMC3013259/

Aboud, F. E., Hossain, K., \& O'Gara, C. (2008). The Succeed Project: challenging early school failure in Bangladesh. Research in Comparative and International Education, 3(3), 295-307. http://dx.doi.org/10.2304/rcie.2008.3.3.295

Aboud, F. E., \& Akhter, S. (2011). A cluster randomized evaluation of a responsive stimulation and feeding intervention in rural Bangladesh. Pediatrics, 127(5), e1191-e1197.

Aboud, F. E., \& Hossain, K. (2011). The impact of pre-primary school on primary school achievement in Bangladesh. Early Childhood Research Quarterly, 26(2), 237-246. https://doi.org/10.1016/j.ecresq.2010.07.001

Akther, N. et al. (2017). Child Care Practice of Mother of below Five Years Children in a Selected Semi Urban Area of Bangladesh. Delta Medical College Journal, 5(2), 76-82. 
https://doi.org/10.3329/dmcj.v5i2.33345

Arnold C., Bartlett, K., Gowani, S., \& Shallwani, S. (2008). Transition to School: Reflections on Readiness. The Journal of Developmental Processes, 3(2).

Barnett, W. S. (1995). NICHD Early Child Care Research Network (1997). Retrieved from http://www.acf.dhhs.gov/programs/ccb/data/index.htm

Blau, D., \& Currie, J. (2004). Preschool, Day Care, and After School Care: Who's Minding the Kids? NBER Working Paper \# 10670, Cambridge MA.

Boyd, J. et al. (2005). Promoting Children's Social and Emotional Development through Preschool Education. National Institute for Early Education Research.

Bradley Scott, M. A. (1998). Snapping Synapses in the Early Years. IDRA Newsletter, April 1998. Retrieved from http://www.idra.org

Chinen, M., \& Bos, J. M. (2016). Impact Evaluation of the Save the Children Early Childhood. Stimulation Program in Bangladesh, Final Report. American Institute for Research: Washington D. C.

Chowdhary, N. N., \& Rivalland, C. (2011). Conceptualizing play as pedagogy in the ECE context of a developing country: The case study of Bangladesh. MIER Journal of Educational Studies, Trends and Practices, 1(2), 171-186.

Chowdhary, N. N., \& Rivalland, C. (2012). Value of play as an early learning instrument in Bangladesh context: A socio-cultural study. Australasian journal of early childhood, 37(4), 115-122.

Denboba, et al. (2014). Stepping up Early Childhood Development: Investing in Young Children for High Returns. Washington, DC: World Bank.

Duflo, E. (2001). Schooling and Labor Market Consequences of School Construction in Indonesia: Evidence from an Unusual Policy Experiment. American Economic Review, 91, 795-813. https://doi.org/10.1257/aer.91.4.795

Early Childhood Development Action Network (ECDAN) (2018). Thrive: Nurturing Care Framework for Early Childhood Development. Country profiles for Early Childhood Development, 15. Retrieved from https://www.ecdan.org/bangladesh.html

Entwisle, Doris, R. (1995). The Role of Schools in Sustaining Early Childhood Program Benefits. The Future of Children, 5(3).

Heckmen, J. J. (2007). Importance of early childhood development. Encyclopedia of Early Childhood Development. Retrieved from http://www.child-encyclopedia.com/sites/default/files/dossiers-complets/en/importanceof-early-childhood-development.pdf

Jacinta, R. M., \& Rotich, K. S. (2015). Impact of Early Childhood Education on Pupils' Learning in Primary Schools in Kenya. Global Journal of Educational Studies, 1(1), 
52-61. https://doi.org/10.5296/gjes.v1i1.7686

Khanom, F. et al. (2013). An Investigation on Effectiveness of a Comprehensive Child Development Package. Bangladesh Education Journal, 12(2).

Magnuson, A., Ruhm, C., \& Waldfogel, J. (2005). Does Prekindergarten Improve School Preparation and Performance? Economics of Education Review, forthcoming.

Ministry of Primary and Mass Education (MoPME). (2013). Country Report on Early Childhood Care and Education in Bangladesh. Retrieved from ecd-bangladesh.net/document/documents/Country_Report_ECCE_Bangladesh.pdf

Moore, A. C., Akhter, S., \& Aboud, F. E. (2008). Evaluating an improved quality preschool program in rural Bangladesh. International Journal of Educational Development, 28, 128-131.

Nath, S. R., \& Sylva, K. (2007). Children's access to pre-school education in Bangladesh. International Journal of Early Years Education, 15(3). http://dx.doi.org/10.1080/09669760701516967

Nath, S. R. et al. (2013). New Vision Old Challenges: The State of Pre-primary Education in Bangladesh. Education Watch 2013. Campaign for Popular Education: Dhaka.

Nahar, S. A., \& Roni, M. R. (2013). Competencies Achieved by Students of an NGO-run Pre-school Program: The Case of Surovi. Bangladesh Education Journal, 12(1).

Naudeau, S., \& Hasan, R. (2015). Early Childhood Development: A Review of the Global Evidence. World Bank: Zambia.

Proulx, K., \& Kabir, S. M. M. (2011). School Readiness: The Effectiveness of Pre-primary Education in Bangladesh. Bangladesh Education Journal, 10(2).

Rashid, R., \& Jahan, N. (in press). Exploring Play-based Pedagogy in Government Pre-primary Classrooms of Bangladesh. Journal of International Research in Early Childhood Education. Melbourne: Monash University.

Rossin-Slater, M. (2015). Promoting Health in Early Childhood. University of California: Santa Barbara. Retrieved from https://pdfs.semanticscholar.org/63a3/256649167842679705c27c664bf5907767a2.pdf

Shahjamal, M. M., \& Nath, S. R. (2008). An Evaluation of BRAC pre-primary Education Programme. BRAC Research and Evaluation Division: Dhaka. Retrieved from https://www.researchgate.net/publication/228774615_An_Evaluation_of_BRAC_Pre-pri mary_Education_Programme

Siddiqi, A., Irwin, L., \& Hertzman, C. (2007). Total environment assessment model for early child development: Evidence report for the World Health Organization's Commission on the Social Determinants of Health. Vancouver, BC: Human Early Learning Partnership (HELP). 


\section{Macrothink Institute ${ }^{\text {TM }}$}

Sikder, S., \& Banu, L. F. A. (2018). Early Childhood Care and Education in Bangladesh: A Review of Policies, Practices and Research. In: Fleer M., van Oers B. (eds) International Handbook of Early Childhood Education. Springer International Handbooks of Education. Springer, Dordrecht. https://doi.org/10.1007/978-94-024-0927-7_26

The Consultative Group on Early Childhood Care and Development (CGECCD). (2013). A Transformative Solution: Reducing Poverty and Inequality through a Post-2015 Early Childhood Development Goal. Retrieved from https://www.unicef.org/earlychildhood/files/CGA_Transformative_Solution_Post_2015 _and_ECD.pdf

UNESCO. (2006). Strong Foundations: Early Childhood Care and Education. Bangladesh Early Childhood Care and Education (ECCE) programmes, Education for All Global Monitoring 2007. Report Retrieved from www.unesco.org/education/GMR/2007/2007_programme.pdf

UNICEF. (2010). Early Learning for Development in Bangladesh: Key Statistics. UNICEF Bangladesh. Retrieved from https://www.unicef.org/bangladesh/Early_Learning_for_Development.pdf

UNESCO. (2015). Pre-primary Education and the School Learning Improvement Plan in Bangladesh. Case Study. UNESCO: Bangkok.

United Nations. (2010). Status of the Convention on the Rights of the Child.

World Bank. (2017). Bangladesh Building the Human Capital of Tomorrow: An Impact Evaluation of the Early Childhood Stimulation Program. World Bank: Washington D. C.

Zaman, S. S. et al. (2015). Effects of a Center Based Comprehensive Child Development Program (CCDP) on Early Child Development at Community Level in Rural Bangladesh. Report (Mid-Time Point). BRAC University: Dhaka.

\section{Copyright Disclaimer}

Copyright for this article is retained by the author(s), with first publication rights granted to the journal.

This is an open-access article distributed under the terms and conditions of the Creative Commons Attribution license (http://creativecommons.org/licenses/by/3.0/). 